\begin{tabular}{|c|l|}
\hline Title & Postnatal growth and development in Sorex unguiculatus \\
\hline Author(s) & Nesterenko, V ladimir; Ohdachi, Satoshi D. \\
\hline Citation & $\begin{array}{l}\text { Mammal Study, 26(2), 145-148 } \\
\text { https://doi.org/10.3106/mammal study.26.145 }\end{array}$ \\
\hline Issue Date & 2001 \\
\hline Doc URL & http://hdl.handle.net/2115/44408 \\
\hline Type & article \\
\hline File Information & MS26-2_145-148.pdf \\
\hline
\end{tabular}

Instructions for use 


\title{
Postnatal growth and development in Sorex unguiculatus
}

\author{
Vladimir Nesterenko ${ }^{1}$ and Satoshi D. Ohdachi ${ }^{2}$ \\ 'Institute of Biology and Soil Science, Vladivostok 690022, Russia \\ ${ }^{2}$ Institute of Low Temperature Science, Hokkaido University, Sapporo 060-0819, Japan
}

The postnatal growth period is of central interest for an understanding of the life histories of altricial mammals. Among the soricine shrews (Soricidae, Insectivora), however, there is only limited information available concerning the postnatal development of a few species (Crowcroft 1957; Harper 1977; Churchfield 1990; Innes 1994). In the long-clawed shrew Sorex unguiculatus Dobson, for example, there have been no reports of direct observations of postnatal growth and development although Okhotina (1984), Inoue (1990), and Nesterenko (1999) estimated the length of the postnatal period of this species, inferring from indirect observations. In the present paper, we describe our direct observations of the growth and development throughout the postnatal growth period of captive $S$. unguiculatus.

\section{Materials and methods}

A pregnant $S$. unguiculatus that had over-wintered was captured in the Experimental Forest of Forestry and Forest Products Research Institute in Sapporo on 31 August 2000. Immediately after capture, she was moved to a laboratory at the Institute of Low Temperature Science, Hokkaido University, Sapporo, where she gave birth to six neonates in the early morning of 1 September 2000.

The family of shrews was kept in a semi-open house under natural conditions of temperature and daylight. A mixed paste diet (Ohdachi 1994) and water were supplied ad libitum. In addition the artificial diet was supplemented with living earthworms (Lumbricidae) or frozen silkworm (Bombyx mori) pupae every day. At first, the mother and neonates were kept together in a plastic cage $(35 \mathrm{~cm} \mathrm{~L} \times 20 \mathrm{~cm} \mathrm{~W} \times 25 \mathrm{~cm} \mathrm{H})$, containing a wooden nest box, an exercise wheel, and sawdust on the floor (see Ohdachi 1994). They were moved, when the young became 23 days old, into a larger cage $(65 \mathrm{~cm} \mathrm{~L} \times 35 \mathrm{~cm} \mathrm{~W} \times 35 \mathrm{~cm} \mathrm{H})$, containing four nest boxes with $10-\mathrm{cm}$ deep soil covered with sawdust. Food and water trays were placed near each nest box. The young were separated from their mother and kept individually once they were 29 days old.

Once neonates reached three days old they were weighed to the nearest $0.1 \mathrm{~g}$ using a portable electronic balance every second day. Body length was measured every third day by placing a neonate on a sheet of graph paper $(1 \mathrm{~mm} \times 1 \mathrm{~mm}$ square). As individual siblings were not marked, individual growth could not be followed, except for those individuals identifiable by particular physical features. In this report, the sex of the newborn shrews was not determined.

\footnotetext{
${ }^{2}$ To whom correspondence should be addressed. E-mail: ohd@pop.lowtem.kokudai.ac.jp
} 


\section{Results and discussion}

\section{Growth}

Six neonates each weighed $0.6 \mathrm{~g}$ on the day of their birth. During the first four days their weights increased rather slowly (Fig. 1). At two days old, two runts weighed just $0.8 \mathrm{~g}$ while the four larger young each weighed $1.0 \mathrm{~g}$. The mother showed no concern for the two smaller neonates and they died aged three and four days old. After the litter size was reduced, the remaining young shrews began to grow rapidly, and the subsequent eight day period was the stage of most rapid growth of the young.

At 15 days old, three of the four surviving siblings reached body weights of $6.7 \mathrm{~g}$ and $6.8 \mathrm{~g}$, while the fourth youngster weighed $6.6 \mathrm{~g}$ (Fig. 1). At 17 days, the difference in body weight had increased, with the larger siblings weighing $7.8 \mathrm{~g}$ and $7.9 \mathrm{~g}$, and the smallest weighing $7.2 \mathrm{~g}$. Finally, the smallest died when it was 18 days old (Fig. 1).

The growth curve of the three remaining siblings almost attained an asymptote when they were 23 days old (Fig. 1). At 29 days old, the three surviving young weighed 9.5, 9.6, and $9.7 \mathrm{~g}$.

\section{Development}

At birth, the neonates were naked, blind and inactive, and had an average body length of $14.3 \pm 0.82(S D) \mathrm{mm}$ (Fig. 2). Sparse hairs appeared at six days of age (Fig. 2). At first, there were only two spots of brown-grayish down on the dorsal surface. At 12 days old, the dorsa of all neonates were covered with short fur, similar in form and color to their mother's, whereas the abdomen was still covered with gray down. Juvenile pelage was complete at 15 days old (Fig. 2). Upper incisors and unicuspids began to erupt as tiny yellow-brownish cusps at 12 days old (Fig. 2). Lower incisors and unicuspids appeared at 15 days. The molars were not observed. Their eyes opened at 15 days of age (Fig. 2).

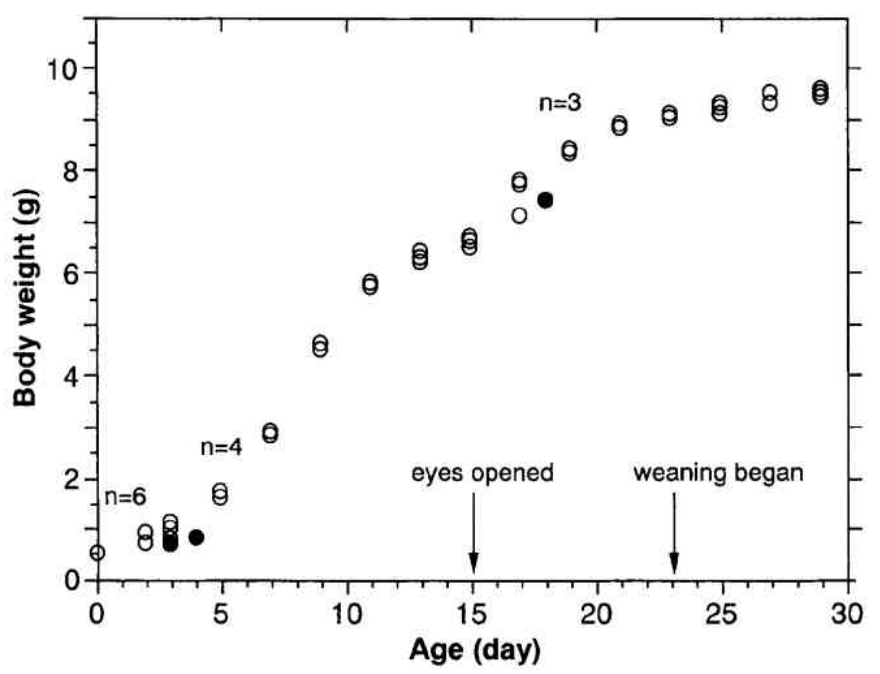

Fig. 1. Body weight of sibling neonate Sorex unguiculatus from birth to weaning. Solid circles denote dead individuals. 


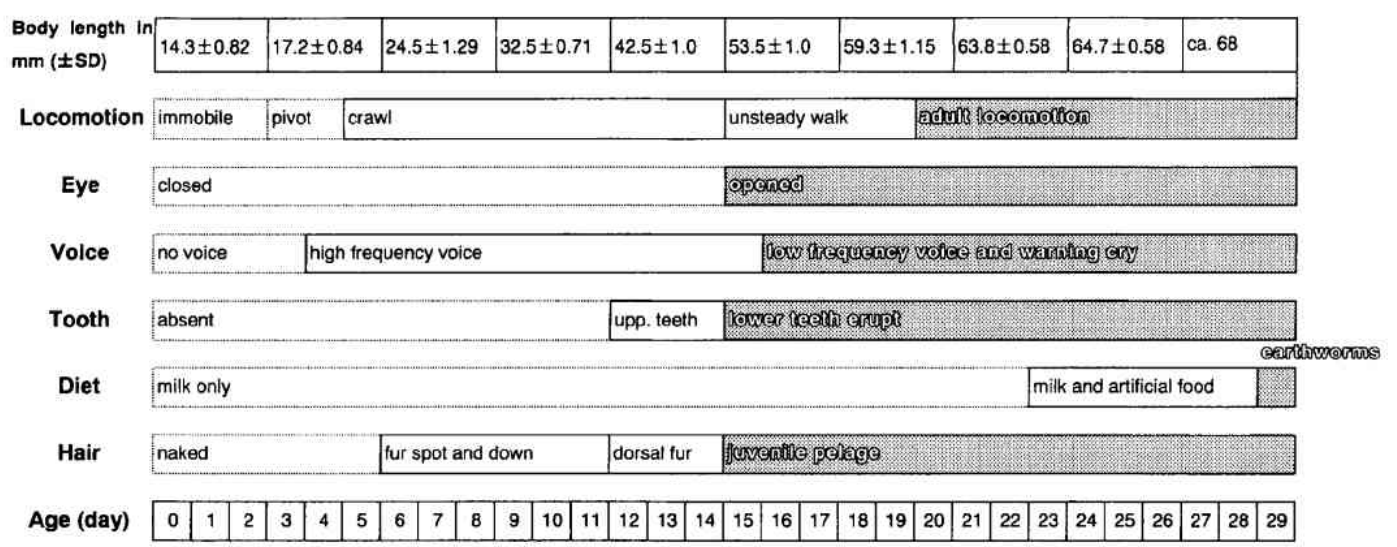

Fig. 2. Postnatal development and body length (head \& body length) of sibling neonate Sorex unguiculatus.

The movements of the young were awkward and mainly confined to suckling during the first three days of life, but became more coordinated after the third day (Fig. 2). In the absence of their mother, they turned, crawling over and underneath each other. The siblings started to crawl around inside the nest from five days old. The young shrews became more active once their eyes had opened at 15 days old. By 20 days old, all the young could walk steadily in adult fashion.

Before four days old, we were unable to detect any vocalisations. From four days old onwards, their calls were audible to the observers' ears. When the female left the nest for feeding, the young uttered sharp squeaky calls. At 16 days old, they gave relatively loud, low frequency warning calls when disturbed.

\section{Mother-young interaction}

While the young were still unable to wander outside the nest box, their mother responded immediately to their calls and quickly returned to nurse them. The day after their eyes opened, the young began frequently to leave the nest. We did not observe "caravanning", which has been described for wild Sorex shrews (Harper 1977). When the young were 20 days old, we observed maternal retrieval behavior, whenever the most active young ventured from the nest and became lost. When it cried loudly, its mother tried to drag it by the scruff of the neck, but it was too heavy for her to pull. As a result, she simply pushed it along to the nest. Subsequently the young found the way to the nest by themselves.

We were not able to observe the precise period of weaning from milk to solid food; however, after the young were 23 days old, the mother was seen drawing a food tray to the nest box entrance every day and trying to pull it inside. Sometimes, she also pulled earthworms into the nest box, consumption of which by the young was confirmed after they were 29 days old. Thus, the young seem to begin to eat solid foods after they are 23 days old. We did not observe lip-licking behavior, which has been observed in other soricine shrews (Churchfield 1990).

After the female and the three infants were moved to a larger cage with four nest boxes, the mother spent two thirds of her time making underground passages. In the first two days after moving to the new cage, she occupied one nest box while the three young remained 
together in another. She continued to visit the young and regularly suckled them until they were 28 days old. At 29 days old, suckling ceased and the young started to eat only solid food (Fig. 2). Although some infants still tried to suckle, their mother quickly discouraged it.

Until they were 28 days old, the young gathered together in a single nest box at night for warmth and contact, but in the daytime they preferred to hide in the burrows made by their mother. After they were 28 days old, the young began to wander outside the nest box at night. No aggressive behavior was observed among the siblings or between them and their mother.

\section{Independence}

The body weights of the young shrews reached an asymptote and they began to ingest solid artificial food at 23 days old (Figs. 1 and 2), and they began to eat earthworms at 29 days old. These facts indicate that weaning of young S. unguiculatus occurs between days 23 and 29 and that they attain physical maturity and become completely independent when 29 days old.

Acknowledgements: We thank Hirofumi Hirakawa for arranging for the capture of shrews in the Experimental Forest of the Forestry and Forest Products Research Institute; Kazumi Matsubara and Yukako Naito for assisting in field work; Sara Churchfield, Mikhail Tiunov, and Sergei Samoilov for reviewing earlier drafts of the manuscript; and Mark Brazil for polish of English.

\section{References}

Churchfield, S. 1990. The Natural History of Shrews. A \& C Black, London, 178 pp.

Crowcroft, P. 1957. The Life of the Shrew. Max Reinhardt, London, $166 \mathrm{pp}$.

Harper, R. J. 1977. “Caravanning” in Sorex species. Journal of Zoology, London 183: 541-542.

Innes, D. G. L. 1994. Life histories of the Soricidae: a review. In (J. F. Merritt, G. L. Kirkland, Jr. and R. K. Rose, eds.) Advances in the Biology of Shrews (Carnegie Museum of Natural History Special Publication 18). Pp. 111-129. Carnegie Museum of Natural History, Pittsburgh.

Inoue, T. 1990. [A Study of the Social Structure and Life History of the Long-clawed Shrew (Sorex unguiculatus Dobson), with Special Reference to Sexual Differences in Dispersal from the Birth Place in the Young.] Doctoral thesis, Graduate School of Agriculture, Hokkaido University, Sapporo. Pp. 134. (in Japanese).

Nesterenko, V. A. 1999. Insectivores of the South Far East and Their Communities. Dalnauka, Vladivostok, 173 pp. (in Russian).

Ohdachi, S. 1994. Total activity rhythms of three soricine species in Hokkaido. Journal of Mammalogical Society of Japan 19: 89-99.

Okhotina, M. V. 1984. Order Insectivora. In Land Mammals of the Far East of USSR. Pp. 31-72. Nauka, Moscow (in Russian). 